Article

\title{
Predictive Direct Power Control for Dual-Active-Bridge Multilevel Inverter Based on Conservative Power Theory
}

\author{
Azuwien Aida Bohari ${ }^{1}{ }^{(D}$, Hui Hwang Goh ${ }^{2} * \mathbb{1}$, Agustiono Kurniawan Tonni ${ }^{3,4}$, Sze Sing Lee ${ }^{5}$, \\ Sy Yi Sim ${ }^{1}$, Kai Chen Goh ${ }^{1}{ }^{10}$, Chee Shen Lim $^{6}$ and Yi Chen Luo ${ }^{2}$ \\ 1 Department of Electrical Power Engineering, Universiti Tun Hussein Onn Malaysia, Batu Pahat 86400, \\ Malaysia; azuwienaidabohari@gmail.com (A.A.B.); sysim@uthm.edu.my (S.Y.S.); \\ kaichen@uthm.edu.my (K.C.G.) \\ 2 School of Electrical Engineering, Guangxi University, Nanning 530004, China; 1912301039@st.gxu.edu.cn \\ 3 Key Laboratory of the Coastal and Wetland Ecosystems, Ministry of Education, College of the Environment \\ and Ecology, Xiamen University, Xiamen 361102, China; tonni@xmu.edu.cn \\ 4 China-ASEAN College of Marine Sciences, Xiamen University Malaysia, Sepang 43900, \\ Selangor Darul Ehsan, Malaysia \\ 5 Newcastle Research \& Innovation Institute, Newcastle University in Singapore, Singapore 609607, Singapore; \\ szesing.lee@ncl.ac.uk \\ 6 School of Electronics and Computer Science, University of Southampton, Malaysia Campus, Nusajaya 79200, \\ Malaysia; C.S.Lim@soton.ac.uk \\ * Correspondence: hhgoh@gxu.edu.cn; Tel.: +86-13299418218
}

Received: 9 May 2020; Accepted: 4 June 2020; Published: 9 June 2020

Abstract: This paper explores the feasibility of multilevel dual-active bridge-inverter (DABMI) applications for grid-connected applications of a modern Model of Predictive Direct Power Control (MPDPC) based on the conservative power theory (CPT). In the case of unbalanced grid voltages, the objective of the study is to promote continued active and reactive energy in MPDPC without reducing efficiency such as transient response and current harmonics. The nature of the instantaneous $p-q$ theory permits only one out of three control targets to be fulfilled. The proposed control approached directly regulates the instantaneous active and reactive power to achieve three particular control objectives namely sinusoidal and symmetrical grid current, cancelling twice of fundamental grid frequency reactive power ripples, and removing twice grid frequency active power ripple. The techniques of complicated Grid part sequence extraction are unnecessary and improved at no extra expense, as is the case with current MPDPC fault-tolerant approaches. The instantaneous power at the next sampling instant is predicted with the newly developed discrete-time model. Each possible switching state will then be evaluated in the cost function defined until the optimal state which lead to the minimum power errors is determined. In MATLAB/Simulink simulation, the proposed CPT-based MPDPC measures reliability and performance at balanced and unbalanced grid voltages then compared with the conventional and existing MPDPC The proposed method manages to achieve all of three control targets which generates sinusoidal grid currents and attenuates active and reactive power ripple of twice the grid frequency exactly at the same time without losing its critical efficiency including transient reaction and current harmonics.

Keywords: unbalanced grid voltage; multilevel inverter; grid-connected application

\section{Introduction}

Taking into account the significance of incorporating intermittent renewable energy sources within the utility grid, comprehensive studies have been carried out [1] to develop a successful control system 
for grid-connected power electronic inverters for facing different unfavorable grid conditions. One of the common undesirable grid disturbances that are experienced in renewable energy systems is voltage unbalance. Grid-tied inverter vulnerability gives rise to unbalanced grid voltage issues, which has compelled the research to move in the direction of unchartered fields. The actual approach to the issue related to critical power oscillation and non-sinusoidal current waveform has till now been restricted to conventional current management strategy, in which proportional-integral controllers [2,3] and proportional-resonant controllers [4] are used in the rotating and stationary reference frames. There are bottlenecks in these controllers in accomplishing multiple control objectives, even though they have complex design with a cascaded configuration. Their dynamic response is low and requires a phase lock loop (PLL) to become synchronous with the power grid [5]. Altering Table-based direct power control $[6,7]$ will decrease the outcome when non-linear hysteresis comparator has been used $[8,9]$.

In the recent times, model predictive control (MPC) that involves simple, high-dynamic features and easy inclusion of restrictions and nonlinearities [10] seems to be a potential technique in comparison to the conventional controller mentioned previously. There has been extensive testing and implementation of the MPC in motor drivers, rectifiers, grid side inverters and various other fields to decrease existing harmonics distortion and to improve the performance of dynamic reaction [11]. It is possible to easily incorporate the idea of MPC into current control or direct power control to form what is known as model predictive direct current control (MPDCC) [12] or MPDPC [13,14].

One of the biggest challenges in order to make the converter operated in normal mode is the unbalanced grid voltage conditions. However, only a handful of them is discussing this topic. To handle the problem that lies in the non-ideal grid condition, a new control method has been proposed in $[15,16]$ where the positive and negative sequence current will be controlled separately that resulting in low stability of the system and reduce the transient response. So far, no studies have investigated the performance of MPDPC for DABMI during non-ideal grid condition. It was found in the earlier studies, in terms of the unbalanced network conditions, that the typical solution in MPCC and MPDPC could determine the latest current or power references from the decomposition method for positive- and negative-sequence grid constituents [12,17]. The decomposition process essentially requires achieving the requirements of PLL, pulse-width modulation (PWM) or other complex extraction methods [18]. Sequence extraction methods [19] and PPL are not needed in [20,21]; however, it is essential to have power compensation strategy to accomplish sinusoidal current waveform, and simultaneously, there will be removal of the double grid frequency oscillations that is present in active as well as reactive powers. This inescapably gives rise to computational intricacy and significant tuning work. Hence, these MPC mechanisms may not be the most appropriate alternatives in various practical applications.

The literature review on the unbalanced fault-ride across the controller that shows the capability to manage unbalanced grid demonstrates that the same power concept is used in the studies. Instantaneous p-q theory was put forward by Akagi in [22], which is often used by the researchers. Selective control targets can be attained by the controllers while the network is imbalanced, for example oscillation-free active power and oscillation free-reactive power, as well as symmetrical and sinusoidal grid current $[17,23]$. Though it is capable of performing well, the instantaneous $p-q$ theory is such that it allows just one out of three control targets to be achieved.

The uniqueness of this study can be demonstrated by putting forward a new power theory called the conservative power theory (CPT). This theory puts forward a novel concept to describe power and current terms [24]. This concept asserts that either voltage or current determines power in a conservative manner. One of the technological values of the CPT is that in the ABC stationary frame, every constituent linked to the electrical attribute of the load would be decomposed by the orthogonal decomposition of the current and power. There are five orthogonal elements, which are: the unbalanced reactive and active currents, the balanced reactive and active currents [25] and the void current that is decomposed when the CPT concept is applied. Because of this quality, the CPT becomes a powerful candidate for selective compensation so that the power quality in distributed generation 
mechanisms [26,27], like microgrids [28] and smart grids [29,30] can be enhanced. When the CPT is included in the MPC, the study would enter into a research field that has not been examined previously.

The CPT concept is correctly incorporated into a restructured MPDPC in this paper to deal with the unbalanced grid voltage issue. MPDPC is supported, rather than MPCC, to prevent the extreme computational intricacy that is brought about due to the extensive mathematical functions for determining the decomposed current elements of CPT [31]. The novel CPT-based MPDPC structure used in a dual-active-bridge multilevel inverter (DABMI) is examined in this study. Two active bridges are used in this arrangement to create multi-level AC voltages [32]. DABMI was one of the developing cascaded converter topologies, which was initially put forward for the open-winding-based induction machine drive system [33]. Using the transformer to offer voltage isolation enhances voltage boosting ability, which additionally supports using this topology for grid-connected renewable energy mechanisms [34]. The control approach put forward is theoretically quite simple and involves a very small change to the traditional MPDPC. In contrast to the traditional MPDPC that uses the instantaneous p-q theory, the MPDPC put forward attains complete sinusoidal and symmetrical grid currents that successfully reduce the power oscillations in the instantaneous active power and instantaneous reactive powers when the grid voltage is unbalanced, in the absence of complex power compensation methods.

\section{Topology of Dual-Active-Bridge Multilevel Inverter (DABMI)}

Some critical issues regarding single-phase DABMI topology shown in Figure 1 are initially described, before dealing with the operational principle of a three-phase DABMI. It should be observed that every active bridge includes two power switches that are linked in the half-bridge connection, with S1 and S2 forming the for most half-bridge configuration, whereas S1' and S2' form the second half-bridge arrangement. As the upper and lower switches in every active bridge work in a complementary mode, the output voltage of every active bridge either functions as on-state or off-state, referred to as ' 1 ' and ' 0 ', correspondingly. As shown in Table 1 , a single-phase DABMI arrangement has the ability to generate up to four distinct AC voltage levels.

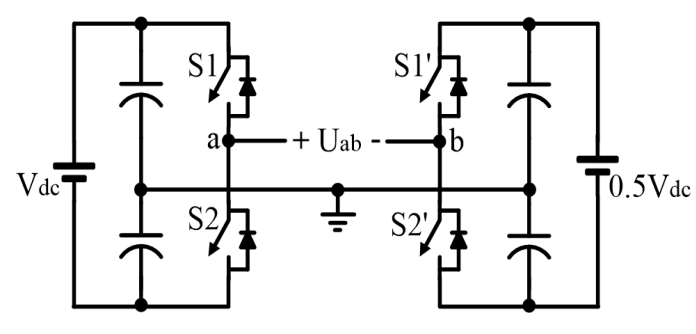

Figure 1. Topology of a single-phase DABMI.

Table 1. Voltage levels generated by a single-phase DABMI.

\begin{tabular}{ccccc}
\hline $\mathbf{S 1}$ & $\mathbf{S 1}^{\prime}$ & $\boldsymbol{U}_{\boldsymbol{a}}$ & $\boldsymbol{U}_{\boldsymbol{b}}$ & $\boldsymbol{U}_{\boldsymbol{a} \boldsymbol{b}}$ \\
\hline 1 & 1 & 0.5 & 0.25 & 0.25 \\
1 & 0 & 0.5 & -0.25 & 0.75 \\
0 & 1 & -0.5 & 0.25 & -0.75 \\
0 & 0 & -0.5 & -0.25 & -0.25 \\
\hline
\end{tabular}

Note: S2 is complementary of S1 and S2' is complementary of S1'.

This study has examined the three-phase grid-connected DABMI, which is also known as a dual-inverter multilevel inverter. There are two standard two-level inverters in DABMI and these can be seen in Figure 2a. The foremost [35], whereas grid is connected on the transformer's secondary side. The voltage vector created from this dual-inverter topology can be achieved by considering the distinction between the voltage vectors produced by the first inverter and those created by the second 
inverter. The voltage vectors that are obtained after taking into account a transformer with unity turn ratio can be explained as:

$$
u_{\alpha \beta}=\left[\begin{array}{l}
u_{\alpha} \\
u_{\beta}
\end{array}\right]=\frac{2}{3}\left[\begin{array}{ccc}
1 & -\frac{1}{2} & -\frac{1}{2} \\
0 & \frac{\sqrt{3}}{2} & -\frac{\sqrt{3}}{2}
\end{array}\right]\left[\begin{array}{c}
S_{a}-0.5 S_{a}^{\prime} \\
S_{b}-0.5 S_{b}^{\prime} \\
S_{c}-0.5 S_{c}^{\prime}
\end{array}\right] V_{d c}
$$

When Equation (1) is examined for all likely combinations of switching states, 64 space vectors in all are obtained. Identification of all possible states will permit the controller to analyse 37 possible switching states instead of 64 where the remainder are redundant as can be seen in Figure $2 \mathrm{~b}$ resulting in the decrease of the calculation time. DABMI able to generate four-level output voltage waveform by the use of 2:1 dc-link voltage ratio fed to both converters.

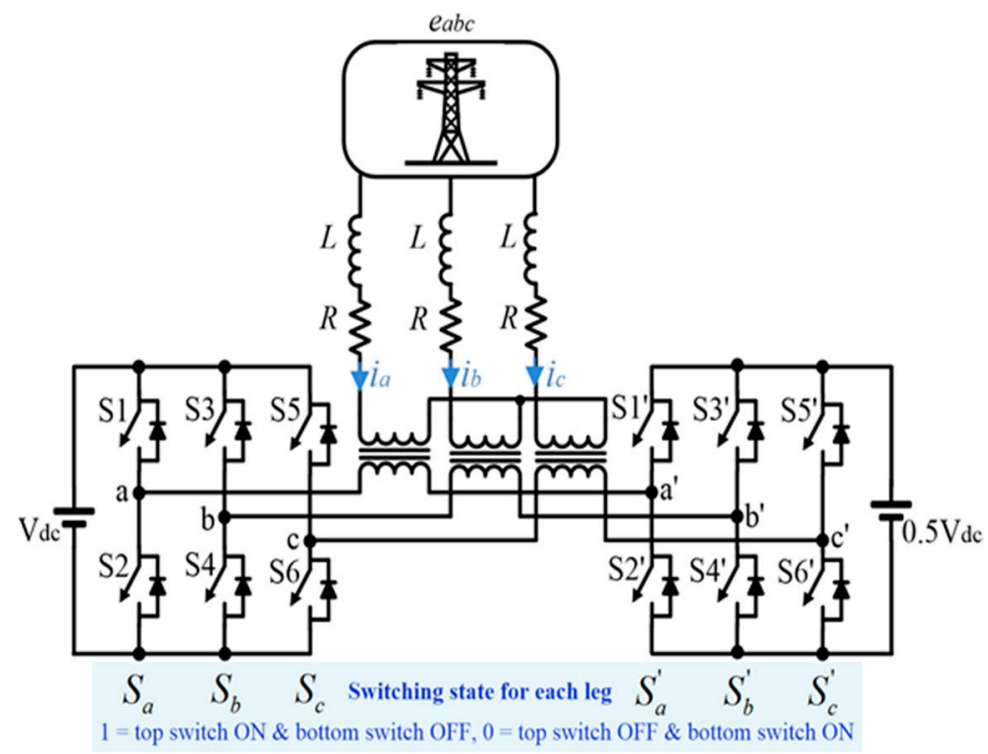

(a)

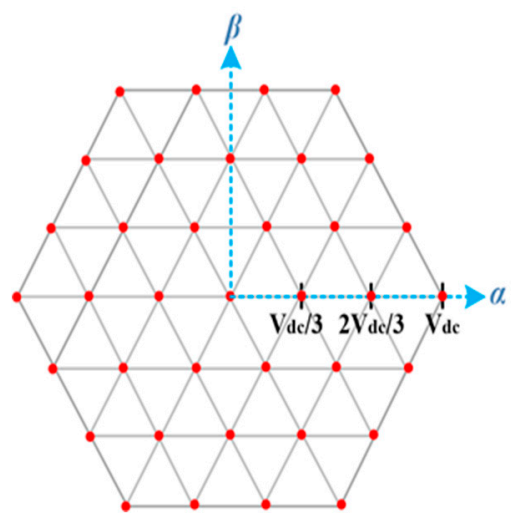

(b)

Figure 2. (a) A grid-connected three-phase DABMI; (b) Space vector representation of a three-phase DABMI.

The three-phase grid connected inverters are usually connected to supply grid phase voltage by inductance $L$ as well as its equivalent series resistance (esr) R [36]. When Kirchoff's voltage law is used in the grid-connected DABMI in Figure 2a, the following equation is obtained:

$$
e_{\alpha \beta}=L \frac{d i_{\alpha \beta}}{d t}+R i_{\alpha \beta}+u_{\alpha \beta}
$$

\section{Methodology}

An outline of the defined instantaneous active and reactive powers is presented in this section for instantaneous $p-q$ theory as well as CPT. Mathematical equations are obtained to explain how the two power theories differ from one another when unbalanced grid voltages are used.

A. Instantaneous $p$-q Theory.

So far, the instantaneous $\mathrm{p}-\mathrm{q}$ theory is the most extensively used power theory. The magnitudeinvariant intricate power $S$ is represented as follows:

$$
S=\frac{3}{2}\left[e_{\alpha \beta} \circ i_{\alpha \beta}+j\left(e_{\alpha \beta} \otimes i_{\alpha \beta}\right)\right]
$$


Here, the symbol $\circ$ indicates the scalar product, while the symbol $\otimes$ signifies the cross product. The following equation is used to signify the active and reactive powers:

$$
\left\{\begin{array}{l}
P=\frac{3}{2} \operatorname{Re}(S)=\frac{3}{2}\left(e_{\alpha} i_{\alpha}+e_{\beta} i_{\beta}\right) \\
Q=\frac{3}{2} \operatorname{Im}(S)=\frac{3}{2}\left(e_{\beta} i_{\alpha}-e_{\alpha} i_{\beta}\right)
\end{array}\right.
$$

B. Selective instantaneous power oscillation elimination during unbalanced grid condition.

This study describes a three-phase three-wire system, in which there is zero current. The symmetric decomposition theory states that it is possible to decompose the positive-, negative- and zero-sequence constituents from the unbalanced three-phase system [37]. In this situation, the zero-sequence constituent is not present, and is even overlooked. Hence, the expression for currents that results from an unbalanced network condition can be dissolved in just the positive and the negative sequence constituents [38], either in the $\alpha \beta$ stationary coordinate system or in the d-q rotating coordinate system, for example:

$$
i_{\alpha \beta}=i_{\alpha \beta}^{+}+i_{\alpha \beta}^{-}=i_{d q}^{+} e^{j \omega t}+i_{d q}^{-} e^{-j \omega t}
$$

The angular frequency $\omega$ is expressed in $\mathrm{rad} / \mathrm{s}$ [39]. It's possible to present the grid voltages in the same way as the grid currents, for example:

$$
e_{\alpha \beta}=e_{\alpha \beta}^{+}+e_{\alpha \beta}^{-}=e_{d q}^{+} e^{j \omega t}+e_{d q}^{-} e^{-j \omega t}
$$

The oscillatory terms that are used in the instantaneous reactive and active powers can be explained more appropriately by presenting a mathematical expression of the grid variables shown in the $\mathrm{d}-\mathrm{q}$ reference frame in a more comprehensive manner. Here, it is possible to decompose the vectors as follows:

$$
\left\{\begin{array}{c}
i_{d q}^{+}=i_{d}^{+}+j i_{q}^{+}, i_{d q}^{-}=i_{d}^{-}+j i_{q}^{-} \\
e_{d q}^{+}=e_{d}^{+}+j e_{q}^{+}, e_{d q}^{-}=e_{d}^{-}+j e_{q}^{-}
\end{array}\right.
$$

When Equations (5)-(7) are substituted into Equation (4), the $P$ and $Q$ expressions under unbalanced network conditions can be presented as positive/negative-sequence components in the following manner:

$$
\left\{\begin{array}{l}
P=P_{0}+P_{c 2} \cos (2 \omega t)+P_{s 2} \sin (2 \omega t) \\
Q=Q_{0}+Q_{c 2} \cos (2 \omega t)+Q_{s 2} \sin (2 \omega t)
\end{array}\right.
$$

Here $\left(P_{0}, Q_{0}\right)$ refer to the DC average values, $\left(P_{\mathrm{c} 2}, Q_{\mathrm{c} 2}\right)$ and $\left(P_{\mathrm{s} 2}, Q_{\mathrm{s} 2}\right)$ signify the cosine and sine oscillatory values respectively, of the instantaneous active and reactive powers [40] at double the grid frequency. The DC average values and oscillatory constituents are additional expressed as shown below:

$$
\begin{gathered}
\left\{\begin{array}{c}
P_{0}=\frac{3}{2}\left(e_{d}^{+} i_{d}^{+}+e_{q}^{+} i_{q}^{+}+e_{d}^{-} i_{d}^{-}+e_{q}^{-} i_{q}^{-}\right) \\
P_{c 2}=\frac{3}{2}\left(e_{d}^{+} i_{d}^{-}+e_{q}^{+} i_{q}^{-}+e_{d}^{-} i_{d}^{+}+e_{q}^{-} i_{q}^{+}\right) \\
P_{s 2}=\frac{3}{2}\left(e_{d}^{+} i_{q}^{-}-e_{q}^{+} i_{d}^{-}-e_{d}^{-} i_{q}^{+}+e_{q}^{-} i_{d}^{+}\right)
\end{array}\right. \\
\left\{\begin{array}{c}
Q_{0}=\frac{3}{2}\left(-e_{d}^{+} i_{q}^{+}+e_{q}^{+} i_{d}^{+}-e_{d}^{-} i_{q}^{-}+e_{q}^{-} i_{d}^{-}\right) \\
Q_{c 2}=\frac{3}{2}\left(-e_{d}^{+} i_{q}^{-}+e_{q}^{+} i_{d}^{-}-e_{d}^{-} i_{q}^{+}+e_{q}^{-} i_{d}^{+}\right) \\
Q_{s 2}=\frac{3}{2}\left(e_{d}^{+} i_{d}^{-}+e_{q}^{+} i_{q}^{-}-e_{d}^{-} i_{d}^{+}-e_{q}^{-} i_{q}^{+}\right)
\end{array}\right.
\end{gathered}
$$

It should be observed that there is no shared relationship between every cosine and sine oscillatory term, that is, $P_{\mathrm{c} 2} \neq P_{\mathrm{s} 2} \neq Q_{\mathrm{c} 2} \neq Q_{\mathrm{s} 2}$. Hence, there is a difference between the oscillation amplitude of the instantaneous active power and the instantaneous reactive power [41]. This indicates that it is not possible to achieve the removal of simultaneous oscillations of the instantaneous active as well as reactive powers [42]. Hence, it is possible to attain just the selective elimination of oscillations in either the instantaneous active power or the instantaneous reactive power. 
Before elaborating CPT concept, it is important to present significant points about the MPDPC in accordance with the instantaneous $\mathrm{p}-\mathrm{q}$ theory. When all oscillatory terms are disregarded, the system will be affected negatively. With respect to the traditional MPDPC, odd-order harmonics is created to compress the oscillatory constituents [14], with the condition that the instantaneous active and reactive powers remain constant. Hence, though there are oscillation-free instantaneous powers, it becomes an incompatible substitute due to the extremely distorted grid currents that emerge from the traditional MPDPC when the operating conditions are unbalanced.

It becomes possible to form sinusoidal currents in MPDPC that uses the instantaneous $p-q$ theory through the power compensation method. This method can decide to achieve two control targets, which are if the instantaneous active power should be removed or the instantaneous reactive power [43]. The former method is fittingly known as active power oscillation compensation (APOC), while the latter is known as reactive power oscillation compensation (RPOC). In the current publication [14], the extensive design and application of power compensations have been elaborated, and so, they are not going to be explained more in this paper. However, the comparative analysis presented in Section 5 will include the previously mentioned customary MPDPC, MPDPC with APOC and MPDPC with RPOC.

C. Conservative power theory (CPT).

The CPT given in [21] is described as follows:

$$
S=\frac{3}{2}\left[e_{\alpha \beta} \circ i_{\alpha \beta}+j\left(\hat{e}_{\alpha \beta} \circ i_{\alpha \beta}\right)\right]
$$

In this equation, symbol $\circ$ represents the scalar product and $\hat{e}_{\alpha \beta}$ refers to the unbiased voltage integral. It can therefore be inferred that the active and reactive instantaneous [35] powers are the real and imaginary components of Equation (10) as indicated follows:

$$
\left\{\begin{array}{l}
P=\frac{3}{2} \operatorname{Re}(S)=\frac{3}{2}\left(e_{\alpha} i_{\alpha}+e_{\beta} i_{\beta}\right) \\
Q=\frac{3}{2} \operatorname{Im}(S)=\frac{3}{2}\left(\hat{e}_{\alpha} i_{\alpha}+\hat{e}_{\alpha} i_{\beta}\right)
\end{array}\right.
$$

It can be observed that the instantaneous real power is equal to the one that is shown in the instantaneous $\mathrm{p}-\mathrm{q}$ theory. The voltage integral of AC element refers to the unbiased voltage integral that does not include the mean value. This is represented as follows:

$$
\hat{e}_{\alpha \beta}=\int_{0}^{T} e_{\alpha \beta}(\tau) d \tau-\bar{e} \int \alpha \beta
$$

In this equation, the foremost term refers to the time integral of grid voltages $e_{\alpha \beta}$, whereas the second term refers to the mean component of the grid voltage integral.

D. Elimination of simultaneous instantaneous power oscillations during unbalanced grid condition.

The following equation is used to represent the positive and negative sequence components [44] that have been decomposed from the unbiased voltage integrals:

$$
\hat{e}_{\alpha \beta}=\hat{e}_{\alpha \beta}^{+}+\hat{e}_{\alpha \beta}^{-}=\int e_{d q}^{+} e^{j \omega t} d t+\int e_{d q}^{-} e^{-j \omega t} d t
$$

The corresponding DC mean values and oscillatory terms are the same in CPT are presented in Equation (9). Two significant observations can be made from the way the four oscillatory terms are presented. It is clear that the oscillatory elements in the instantaneous active power interact with those in the instantaneous reactive power [45]. In other words, $P_{\mathrm{c} 2}=Q_{\mathrm{s} 2}$ and $P_{\mathrm{s} 2}=-Q_{\mathrm{c} 2}$. Therefore, it is not astonishing to observe that the oscillations for instantaneous active and reactive powers are essentially of the same magnitude. This shows that when the oscillatory elements of the instantaneous active power are cancelled, those in the instantaneous reactive power are also simultaneous cancelled. 


\section{MPDPC Based CPT}

In the present-day situation, like the control approaches when there are weak grid conditions, the worst-case situation is caused by unbalanced operating conditions, which continue to cause issues, specifically for high power systems. If there are extensive changes to the quantity of renewable energies, the grid performance would deteriorate. This is why it is imperative to efficiently regulate the power electronic converter so that the consistency of the system is maintained in accordance with the power grid. The proposed algorithm has the main objective of integrating the CPT concept with the MPDPC technique so that the sinusoidal current waveforms can be attained and continuous and oscillation-free active and reactive powers can be generated when grid voltages are balanced and unbalanced. The grid variables are usually expressed in the stationary $\alpha \beta$ reference frame in MPDPC. Equation (11) is differentiated to obtain the equations given below:

$$
\begin{aligned}
& \frac{d P}{d t}=\frac{3}{2}\left(e_{\alpha} \frac{d_{i \alpha}}{d t}+i_{\alpha} \frac{d_{e_{\alpha}}}{d t}+e_{\beta} \frac{d_{i_{\beta}}}{d t}+i_{\beta} \frac{d_{e_{\beta}}}{d t}\right) \\
& \frac{d Q}{d t}=\frac{3}{2}\left(\hat{e}_{\alpha} \frac{d_{i \alpha}}{d t}+i_{\alpha} \frac{d_{\hat{e}_{\alpha}}}{d t}+\hat{e}_{\beta} \frac{d_{i_{\beta}}}{d t}+i_{\beta} \frac{d_{\hat{e}_{\beta}}}{d t}\right)
\end{aligned}
$$

On the basis of the differentiation of the mean component in Equation (12), which is a constant equivalent to zero, it can be effortlessly shown that the following equation depicts the time derivative of the unbiased voltage integrals:

$$
\frac{d_{\hat{e}_{\alpha}}}{d t}=e_{\alpha}, \frac{d_{\hat{e}_{\beta}}}{d t}=e_{\beta}
$$

When Equation (16) is included in Equation (15), it becomes possible to further simply the derivative of the reactive power as:

$$
\frac{d Q}{d t}=\frac{3}{2}\left(\hat{e}_{\alpha} \frac{d_{i \alpha}}{d t}+\hat{e}_{\beta} \frac{d_{i_{\beta}}}{d t}\right)+P
$$

The expression given below is obtained when the relationship between the time derivatives of the grid voltages and the unbiased voltage integrals is examined:

$$
\frac{d_{e_{\alpha}}}{d t}=-\omega \hat{e}_{\alpha}, \frac{d_{e_{\beta}}}{d t}=-\omega \hat{e}_{\beta}
$$

When mathematical computations are carried out on Equation (2), it becomes possible to express the instantaneous current variations as follows:

$$
\left\{\begin{array}{l}
\frac{d_{i \alpha}}{d t}=\frac{1}{L}\left(e_{\alpha}-u_{\alpha}-R_{i \alpha}\right) \\
\frac{d_{i \beta}}{d t}=\frac{1}{L}\left(e_{\beta}-u_{\beta}-R_{i \beta}\right)
\end{array}\right.
$$

The conforming discrete-time representations are deduced from the Forward Euler computation by replacing Equations (16), (18) and (19) in Equations (14) and (17) are denoted as follows:

$$
\begin{aligned}
& P^{k+1}=P^{k}+\frac{3 T_{s}}{2 L}\left\{\left(e_{\alpha}^{k}\right)^{2}+\left(e_{\beta}^{k}\right)^{2}-e_{\alpha}^{k} u_{\alpha}^{k}-e_{\beta}^{k} u_{\beta}^{k}\right\}-\frac{R T_{s}}{L} P^{k}-\omega T_{s} Q^{k} \\
& Q^{k+1}=Q^{k}+\frac{3 T_{s}}{2 L}\left\{\hat{e}_{\alpha}^{k}\left(e_{\alpha}^{k}-u_{\alpha}^{k}\right)+\hat{e}_{\beta}^{k}\left(e_{\beta}^{k}-u_{\beta}^{k}\right)\right\}-\frac{R T_{s}}{L} Q^{k}-T_{s} P^{k}
\end{aligned}
$$

Here, $T_{S}$ refers to the sampling period. Keeping in view the aim of limiting instantaneous power tracking errors, so that the differences between the power references and the expected instantaneous future powers can be reduced, the cost function is represented as: 


$$
g=\left(P^{r e f}-P^{k+1}\right)^{2}+\left(Q^{r e f}-Q^{k+1}\right)^{2}
$$

It needs to be acknowledged that the control approach put forward is quite simple, requiring neither sequences extraction of grid components, nor power compensation approach. It is possible to directly obtain the unbiased voltage integrals by carrying out the mathematical functions in Equation (12). It is also possible to implement a bandpass filter (BPF), which functions as an ideal integrator, instead of the mathematical commands, because it also has the ability to remove the DC component of the grid voltages [18].

The block diagram for the CPT-based MPDPC that has been put forward is demonstrated in Figure 3. To achieve the unbiased voltage integrals, the grid voltages computed are initially fed using a BPF. Thereafter, the unbiased voltage integrals computed, along with the grid currents measured, will be converted into the stationary $\alpha \beta$ coordinate system so that the instantaneous powers can be determined by employing CPT. The subsequent instantaneous power is determined using the newly formulated discrete-time model, given in Equations (20) and (21). The cost function shown in Equation (22) will then be used to assess every possible switching state, till the optimal state is identified, i.e., the one with the least power error. In contrast to the conventional MPDPC, the suggested MPDPC requires a single minor adjustment, which is the inclusion of the CPT concept into the prediction model. When there are significant variations in the extent of renewable energies, the grid performance to regulate the inverter would decrease, and this can precisely maintain the power quality and make it consistent with the power grid [4].

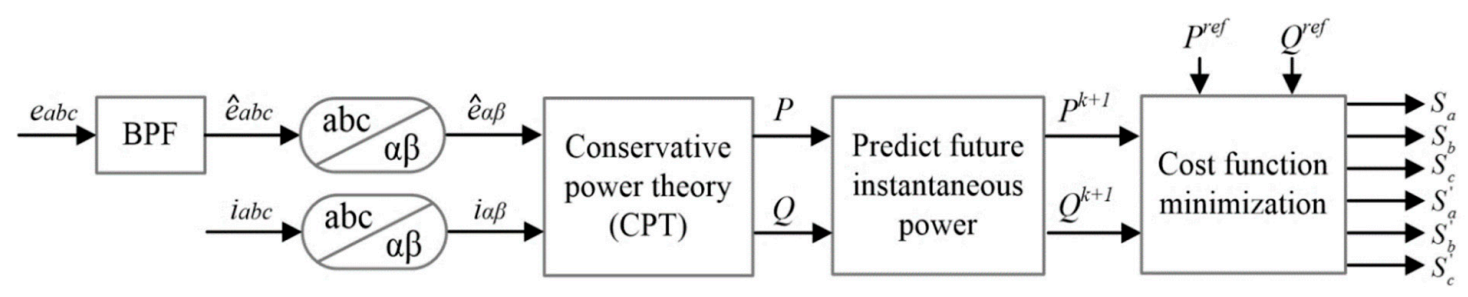

Figure 3. MPDPC based on the CPT concept block diagram.

\section{Simulation Results}

The overall performance enhancements of the suggested control approach in the grid-connected system can be confirmed by carrying out simulations for balanced and unbalanced operating conditions in the MATLAB Simulink [46] software with 0.05 s interval for each condition. The unbalanced operating condition considered in the analysis is achieved by increasing the phase-a grid voltage by $10 \%$ and decreasing the phase- $b$ grid voltage by $10 \%$. The findings of the analysis is further reinforced by the numerical results tabulated in Table 2. Figure 4 shows the waveforms for the traditional MPDPC, MPDPC with APOC, MPDPC with RPOC as well as the proposed MPDPC is kept at $2 \mathrm{~kW}$ and the reactive power reference is kept at 0 Var. It can be seen in the Figure that exceptional power tracking performances are demonstrated by all control strategies under balanced grid voltages. The three-phase currents are controlled in phase with the three-phase [47] grid voltages, which ensures the unity power factor operation for all MPDPC approaches under various operating conditions.

With respect to the unbalanced voltage supply, the reason for the extremely distorted currents in the traditional MPDPC is the presence of significant low-order harmonics, such as the third and fifth components, as can be seen in the current harmonics spectra given in Figure 5a generate by the FFT block in Matlab Sympowersystem. These odd harmonics are developed when consistent instantaneous powers are implemented in the traditional MPDPC, as explained earlier. On the other hand, when the third and fifth harmonics are effectively suppressed, there are sinusoidal current waveforms in MPDPC with APOC, MPDPC with RPOC and the suggested MPDPC. There is constant active power for MPDPC with APOC, and the reactive power oscillates at twice the grid frequency [48]. On the other hand, there are constant and smooth observed instantaneous active and reactive powers in the 
suggested MPDPC, which proves its ability to remove simultaneous power oscillations. The findings obtained are all consistent with the theoretical explanations presented in Section 3.

Table 2. Comparison of different MPDPC methods during balanced and unbalanced grid voltages.

\begin{tabular}{|c|c|c|c|c|}
\hline \multirow{2}{*}{ Methods } & \multicolumn{2}{|c|}{ Conventional MPDPC } & \multicolumn{2}{|c|}{ MPDPC with APOC } \\
\hline & Balanced & Unbalanced & Balanced & Unbalanced \\
\hline THD i (\%) & 1.61 & 6.1 & 1.61 & 1.62 \\
\hline P peak-to-peak $(\mathrm{W})$ & \pm 77.5 & \pm 57.3 & \pm 57.6 & \pm 53.5 \\
\hline \multirow[t]{3}{*}{ Q peak-to-peak (W) } & \pm 58.2 & \pm 61.1 & \pm 58.2 & \pm 272.8 \\
\hline & \multicolumn{2}{|c|}{ MPDPC with RPOC } & \multicolumn{2}{|c|}{ Proposed MPDPC } \\
\hline & Balanced & Unbalanced & Balanced & Unbalanced \\
\hline THD i (\%) & 1.61 & 1.57 & 1.10 & 1.13 \\
\hline P peak-to-peak (W) & \pm 57.9 & \pm 282.3 & \pm 38.6 & \pm 46.9 \\
\hline Q peak-to-peak (W) & \pm 57.8 & \pm 58 & \pm 36 & \pm 39.3 \\
\hline
\end{tabular}

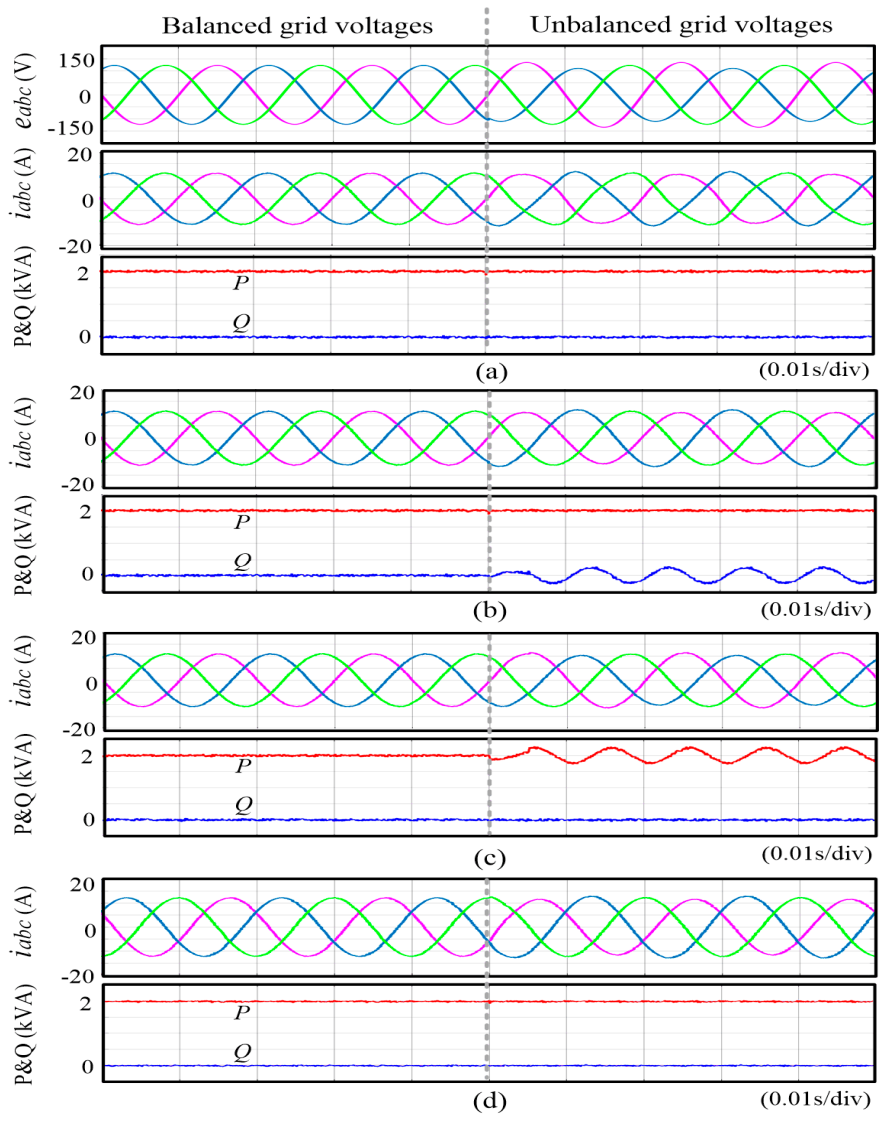

Figure 4. Dynamic responses during balanced and unbalanced grid voltages for (a) conventional MPDPC; (b) MPDPC with APOC; (c) MPDPC with RPOC and (d) the proposed MPDPC.

Since there are theoretical similarities between the CPT-based MPDPC that has been put forward and the traditional MPDPC, it is likely that the inherent rapid transient performance in the traditional MPDPC will be maintained. For verification, a simulation analysis was carried out to assess the transient reactions of all four control techniques, where a stepped adjustment in the reference of active power was present. While the reactive power [49] was maintained at 0 Var the active power reference was changed from $2 \mathrm{~kW}$ to $-2 \mathrm{~kW}$. Identical unbalanced operating condition was used, like in the preceding analysis. By conducting a comparison of performance presented in Figure 6, exceptional dynamic responses having a short settling time of $1.4 \mathrm{~ms}$ was obtained during the active power step 
for the various control techniques discussed. The properties observed for the current and power waveforms for every control approach are consistent with those that were observed for the preceding comparative analysis. It is verified that the CPT-based MPDPC put forward ensures sinusoidal grid currents and oscillation-free instantaneous active and reactive power that monitor performances throughout the time span. It has been found that the improved power quality of the proposed control technique under unbalanced operating condition with the removal of active and reactive power twice grid frequency oscillation is a significant benefit in comparison to the prevailing MPDPC techniques.

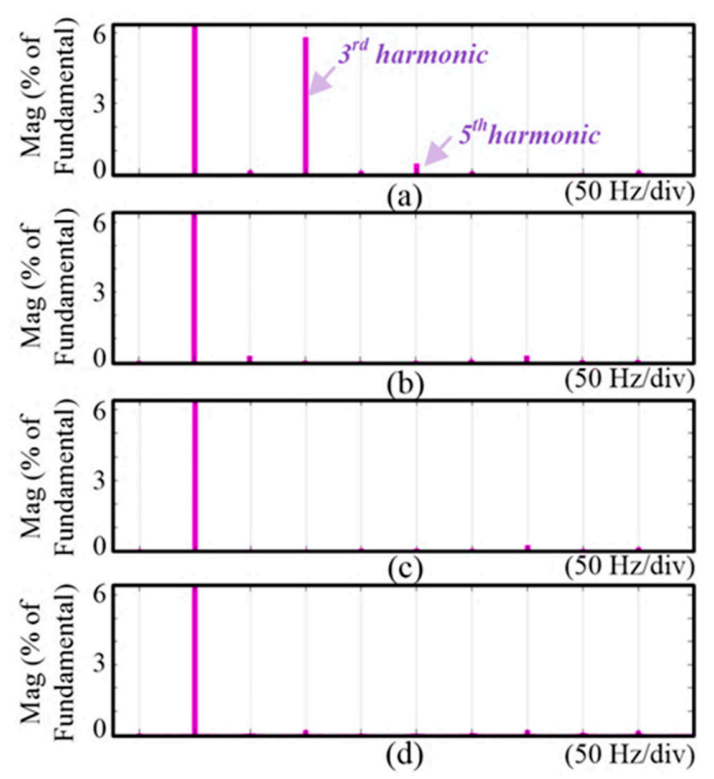

Figure 5. Current spectra during unbalanced grid voltages for (a) conventional MPDPC; (b) MPDPC with APOC; (c) MPDPC with RPOC and (d) the proposed MPDPC.

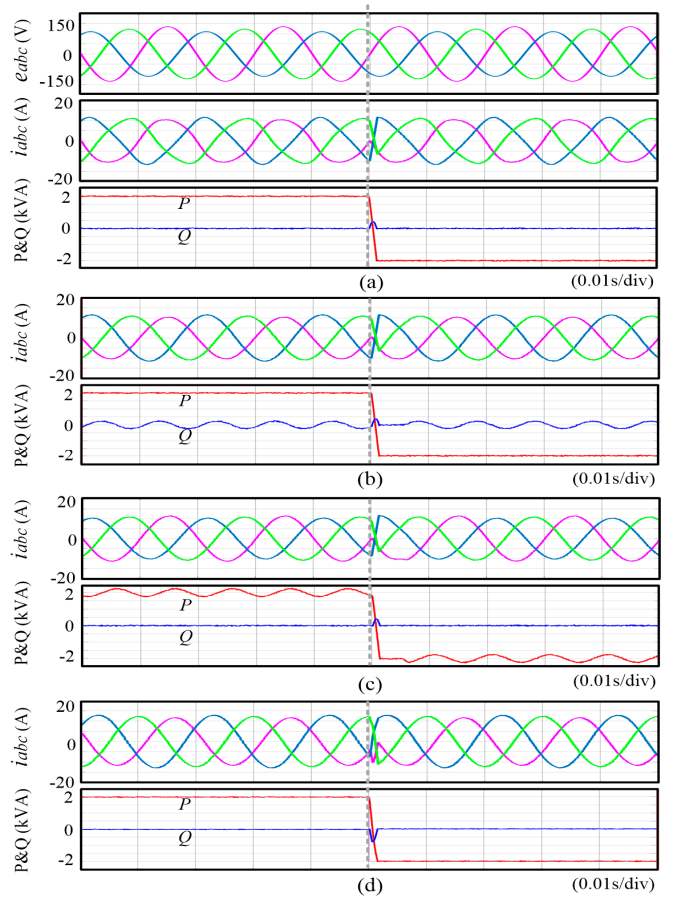

Figure 6. Dynamic responses in active power reference under unbalanced grid voltages to [50] stepped adjustment for (a) conventional MPDPC; (b) MPDPC with APOC; (c) MPDPC with RPOC and (d) the proposed MPDPC. 


\section{Conclusions}

In this study, a new MPC method that incorporates the CPT concept in MPDPC under balanced and unbalanced grid voltage conditions has been presented. It is different from majority [33] techniques that suggested MPDPC has been put forward without the need for a complex sequence extraction of grid constituents, like the PWM and the PLL approach. The suggested MPDPC has the ability to relate various control objectives during unbalanced grid voltages, hence, the proposed control approach has the ability to achieve the three particular control objectives which generate sinusoidal grid currents and reduce twice the amount of grid frequency oscillations in the instantaneous active [51] as well as reactive powers, without having an impact on the significant operational performances, like current harmonics and transient response. In the simulated comparative investigation with the MPDPC techniques that use the instantaneous p-q theory, i.e., the conventional MPDPC without power compensation, MPDPC with APOC as well as the MPDPC with RPOC, the advantages of the CPT-based MPDPC put forward are verified. It is not essential that the MPDPC is restricted to the use of just DABMI; it can also be applicable on any of the grid-tied converter topologies. It is also likely that its use in the three-phase grid-tied converter topologies would deal with the prevailing conventional issues, where the main issue is the unbalanced grid fault.

Author Contributions: H.H.G.: Conceptualization, Methodology, Software. A.A.B.: Data curation, Writing Original draft preparation. H.H.G., A.A.B., K.C.G.: Visualization, Investigation. H.H.G., S.S.L., S.Y.S.: Supervision. G.H.H., S.S.L., A.A.B.: Software, Validation. A.K.T., C.S.L., Y.C.L.: Writing-Reviewing and Editing. All authors have read and agreed to the published version of the manuscript.

Funding: This research was funded by Jun Wu Scholar Grant Scheme, grant number Vot: A3020051008. and the APC was funded by Guangxi University The authors would like to thank the Ministry of Higher Education, Malaysia (MOHE), and Universiti Tun Hussein Onn Malaysia (UTHM) for supporting this research.

Acknowledgments: The authors wish to thank all those who contributed to this study and gave valuable feedback to this research. This research was funded by Jun Wu Scholar Grant Scheme, grant number Vot: A3020051008. and the APC was funded by Guangxi University The authors would like to thank the Ministry of Higher Education, Malaysia (MOHE), and Universiti Tun Hussein Onn Malaysia (UTHM) for supporting this research.

Conflicts of Interest: The authors declare no conflict of interest.

\section{Nomenclature}

$\begin{array}{ll}e & \text { Grid voltage } \\ \hat{e} & \text { Unbiased voltage integral } \\ i & \text { Current } \\ I_{m} & \text { Imaginary } \\ L & \text { Inductance } \\ P & \text { Active Power } \\ Q & \text { Reactive Power } \\ R & \text { Resistance } \\ R_{e} & \text { Real } \\ S & \text { Magnitude invariant complex power } \\ T_{S} & \text { Sampling Period } \\ V_{d c} & \text { DC side voltage } \\ \omega & \text { Grid frequency }\end{array}$

\section{References}

1. Alyami, S.; Wang, Y.; Wang, C. Adaptive real power capping method for fair overvoltage regulation of distribution networks with high penetration of PV systems. IEEE Trans. Smart Grid 2014, 5, 2729-2738. [CrossRef]

2. Zhang, J.; Zhao, C. Analysis and control of MMC-HVDC under unbalanced voltage conditions. Electr. Power Syst. Res. 2016, 140, 528-538. [CrossRef] 
3. Hu, J.; He, Y. Modeling and enhanced control of DFIG under unbalanced grid voltage conditions. Electr. Power Syst. Res. 2009, 79, 273-281. [CrossRef]

4. Liao, Y.; Li, H.; Yao, J.; Zhuang, K. Operation and control of a grid-connected DFIG-based wind turbine with series grid-side converter during network unbalance. Electr. Power Syst. Res. 2011, 81, 228-236. [CrossRef]

5. Aurtenechea, S.; Rodriguez, M.A.; Oyarbide, E.; Torrealday, J.R. Predictive direct power control—A new control strategy for DC/AC converters. In Proceedings of the IECON 2006-32nd Annual Conference on IEEE Industrial Electronics, Paris, France, 6-10 November 2006; pp. 1661-1666. [CrossRef]

6. Mesbahi, N.; Ouari, A.; Abdeslam, D.O.; Djamah, T.; Omeiri, A. Direct power control of shunt active filter using high selectivity filter (HSF) under distorted or unbalanced conditions. Electr. Power Syst. Res. 2014, 108, 113-123. [CrossRef]

7. Yousefi-Talouki, A.; Pouresmaeil, E.; Jørgensen, B.N. Active and reactive power ripple minimization in direct power control of matrix converter-fed DFIG. Int. J. Electr. Power Energy Syst. 2014, 63, 600-608. [CrossRef]

8. Brando, G.; Dannier, A.; Del Pizzo, A.; Di Noia, L.P.; Spina, I. Quick and high performance direct power control for multilevel voltage source rectifiers. Electr. Power Syst. Res. 2015, 121, 152-169. [CrossRef]

9. Lee, S.S.; Heng, Y.E. Table-based DPC for grid connected VSC under unbalanced and distorted grid voltages: Review and optimal method. Renew. Sustain. Energy Rev. 2017, 76, 51-61. [CrossRef]

10. Kouro, S.; Cortes, P.; Vargas, R.; Ammann, U.; Rodriguez, J. Model predictive control—A simple and powerful method to control power converters. IEEE Trans. Ind. Electron. 2008, 56, 1826-1838. [CrossRef]

11. An, F.; Song, W.; Yu, B.; Yang, K. Model predictive control with power self-balancing of the output parallel dab DC-DC converters in power electronic traction transformer. IEEE J. Emerg. Sel. Top. Power Electron. 2018, 6, 1806-1818. [CrossRef]

12. Hu, J.; He, Y.; Nian, H. Improved predictive current control of grid-connected DC-AC converters under unbalanced grid voltage conditions. In Proceedings of the 2009 IEEE Energy Conversion Congress and Exposition, San Jose, CA, USA, 20-24 September 2009; pp. 1-8. [CrossRef]

13. Lee, S.S.; Heng, Y.E. Predictive direct power control of multilevel direct current link converter for grid connected battery energy storage systems. J. Renew. Sustain. Energy 2016, 8, 034104. [CrossRef]

14. Lee, S.S.; Heng, Y.E. A voltage level based predictive direct power control for modular multilevel converter. Electr. Power Syst. Res. 2017, 148, 97-107. [CrossRef]

15. Ma, K.; Chen, W.; Liserre, M.; Blaabjerg, F. Power controllability of a three-phase converter with an unbalanced AC source. IEEE Trans. Power Electron. 2014, 30, 1591-1604. [CrossRef]

16. Miret, J.; Castilla, M.; Camacho, A.; De Vicuna, L.G.; Matas, J. Control Scheme for Photovoltaic Three-phase inverters to minimize peak currents during unbalanced grid-voltage sags. IEEE Trans. Power Electron. 2012, 27, 4262-4271. [CrossRef]

17. Shang, L.; Sun, D.; Hu, J. Sliding-mode-based direct power control of grid-connected voltage-sourced inverters under unbalanced network conditions. IET Power Electron. 2011, 4, 570. [CrossRef]

18. Schönleber, K.; Prieto-Araujo, E.; Rates-Palau, S.; Gomis-Bellmuntc, O. Handling of unbalanced faults in HVDC-connected wind power plants. Electr. Power Syst. Res. 2017, 152, 148-159. [CrossRef]

19. Sun, S.H.; Ben, H.Q. Modified power compensation control strategy of three-phase grid-connected inverter under unbalanced grid voltage conditions. Appl. Mech. Mater. 2015, 740, 335-338. [CrossRef]

20. Jin, N.; Guo, L.; Gan, C.; Hu, S.; Dou, Z. Finite-state model predictive power control of three-phase bidirectional AC/DC converter under unbalanced grid faults with current harmonic reduction and power compensation. IET Power Electron. 2018, 11, 348-356. [CrossRef]

21. Jin, N.; Hu, S.; Gan, C.; Ling, Z. Finite states model predictive control for fault-tolerant operation of a three-phase bidirectional AC/DC converter under unbalanced grid voltages. IEEE Trans. Ind. Electron. 2017, 65, 819-829. [CrossRef]

22. Akagi, H.; Kanazawa, Y.; Nabae, A. Instantaneous reactive power compensators comprising switching devices without energy storage components. IEEE Trans. Ind. Appl. 1984, 20, 625-630. [CrossRef]

23. Chen, W.; Geng, X.; Liu, T.; Xia, C. Stationary frame deadbeat power control of three-phase PWM rectifiers under unbalanced grid voltages. Electr. Power Syst. Res. 2014, 108, 223-233. [CrossRef]

24. Tenti, P.; Trombetti, D.; Tedeschi, E.; Mattavelli, P. Compensation of load unbalance, reactive power and harmonic distortion by cooperative operation of distributed compensators. In Proceedings of the 2009 13th European Conference on Power Electronics and Applications, Barcelona, Spain, 8-10 September 2009; pp. 1-10. 
25. Marafão, F.P.; Brandão, D.I.; Gonçalves, F.A.S.; Paredes, H.K.M. Decoupled reference generator for shunt active filters using the conservative power theory. J. Control Autom. Electr. Syst. 2013, 24, 522-534. [CrossRef]

26. Tenti, P.; Paredes, H.K.M.; Mattavelli, P. Conservative power theory, a framework to approach control and accountability issues in smart microgrids. IEEE Trans. Power Electron. 2010, 26, 664-673. [CrossRef]

27. Tenti, P.; Paredes, H.K.M.; Marafao, F.P.; Mattavelli, P. Accountability in smart microgrids based on conservative power theory. IEEE Trans. Instrum. Meas. 2011, 60, 3058-3069. [CrossRef]

28. Burgos-Mellado, C.; Hernandez-Cariman, C.; Cardenas, R.; Saez, D.; Sumner, M.; Costabeber, A.; Paredes, H.K.M. Experimental evaluation of a CPT-based four-leg Active power compensator for distributed generation. IEEE J. Emerg. Sel. Top. Power Electron. 2017, 5, 747-759. [CrossRef]

29. Deblecker, O.; Stevanoni, C.; Vallée, F. Cooperative control of multi-functional inverters for renewable energy integration and power quality compensation in micro-grids. In Proceedings of the 2016 International Symposium on Power Electronics, Electrical Drives, Automation and Motion (SPEEDAM), Anacapri, Italy, 22-24 June 2016; pp. 1051-1058. [CrossRef]

30. Brandao, D.I.; Marafao, F.P.; Paredes, H.K.M.; Costabeber, A. Inverter control strategy for DG systems based on the conservative power theory. In Proceedings of the 2013 IEEE Energy Conversion Congress and Exposition, Denver, CO, USA, 15-19 September 2013; pp. 3283-3290. [CrossRef]

31. Mortezaei, A.; Lute, C.; Simões, M.G.; Marafao, F.P.; Boglia, A. PQ, DQ and CPT control methods for shunt active compensators a comparative study. In Proceedings of the 2014 IEEE Energy Conversion Congress and Exposition (ECCE), Pittsburgh, PA, USA, 14-18 September 2014; pp. 2994-3001. [CrossRef]

32. Chowdhury, S.; Wheeler, P.; Gerada, C.; Patel, C. Model predictive control for a dual-active bridge inverter with a floating bridge. IEEE Trans. Ind. Electron. 2016, 63, 5558-5568. [CrossRef]

33. Kawabata, Y.; Yahata, N.; Horii, M.; Ejiogu, E.; Kawabata, T. SVG using open-winding transformer and two inverters. In Proceedings of the 2004 IEEE 35th Annual Power Electronics Specialists Conference (IEEE Cat. No. 04CH37551), Aachen, Germany, 20-25 June 2004; pp. 3039-3044. [CrossRef]

34. Grandi, G.; Ostojic, D.; Rossi, C. Dual inverter configuration for grid-connected photovoltaic generation systems. In Proceedings of the INTELEC 07-29th International Telecommunications Energy Conference, Rome, Italy, 30 September-4 October 2007; pp. 880-885.

35. Bohari, A.A.; Hwang, G.H.; Yi, S.S.; Sing, L.S.; Heng, Y.E. Model predictive direct power control of dual active bridge multilevel inverter during balanced and unbalanced grid voltage. In Proceedings of the 2019 IEEE International Conference on Automatic Control and Intelligent Systems (I2CACIS), Selangor, Malaysia, 29 June 2019; pp. 230-234.

36. Tan, A.S.T.; Ishak, D.; Mohd-Mokhtar, R. Chapter 22 Grid-Connected PV Generator Using Three-Phase VSC with Model Predictive Control; Springer: Berlin/Heidelberg, Germany, 2019.

37. Burgos-Mellado, C.; Llanos, J.J.; Cárdenas, R.; Sáez, D.; Olivares, D.E.; Sumner, M.; Costabeber, A. Distributed control strategy based on a consensus algorithm and on the conservative power theory for imbalance and harmonic sharing in 4-wire microgrids. IEEE Trans. Smart Grid 2020, 11, 1604-1619. [CrossRef]

38. He, Z.; Sun, D.; Shang, L.; Zhu, J. Modified predictive direct power control of voltage-sourced converters under network voltage unbalance conditions. In Proceedings of the 2011 International Conference on Electrical Machines and Systems; Institute of Electrical and Electronics Engineers (IEEE), Beijing, China, 20-23 August 2011; pp. 1-6.

39. Van, T.L.; Truong, T.H.; Cao, M.T.; Nguyen, P.C.; Nguyen, H. Improved control scheme for low voltage ride-through of pmsg-based wind energy conversion systems. In Proceedings of the 2018 4th International Conference on Green Technology and Sustainable Development (GTSD), Ho Chi Minh City, Vietnam, 23-24 November 2018.

40. Hu, J.; He, Y. Modeling and Control of Grid Connected Voltage-Sourced Converters Under Generalized Unbalanced Operation Conditions. IEEE Trans. Energy Convers. 2008, 23, 903-913.

41. Peng, F.Z.; Ott, G.W.; Adams, D.J. Harmonic and reactive power compensation based on the generalized instantaneous reactive power theory for three-phase four-wire systems. IEEE Trans. Power Electron. 1998, 13, 1174-1181. [CrossRef]

42. Furuhashi, T.; Okuma, S.; Uchikawa, Y. A study on the theory of instantaneous reactive power. IEEE Trans. Ind. Electron. 1990, 37, 86-90. [CrossRef] 
43. Timbus, A.V.; Rodriguez, P.; Teodorescu, R.; Liserre, M.; Blaabjerg, F. Control strategies for distributed power generation systems operating on faulty grid. In Proceedings of the 2006 IEEE International Symposium on Industrial Electronics, Montreal, QC, Canada, 9-13 July 2006; pp. 1601-1607. [CrossRef]

44. Bai, Y.; Guo, X.; Wang, B.; Li, Y. Fully digital grid synchronization under harmonics and unbalanced conditions. IEEE Access 2019, 7, 109969-109981. [CrossRef]

45. Drif, M.; Cardoso, A.J.M. Discriminating the simultaneous occurrence of three-phase induction motor rotor faults and mechanical load oscillations by the instantaneous active and reactive power media signature analyses. IEEE Trans. Ind. Electron. 2011, 59, 1630-1639. [CrossRef]

46. Lee, S.S.; Heng, Y.E. A tuning-less model predictive control for modular multilevel converter capable of unbalanced grid fault. Int. J. Electr. Power Energy Syst. 2018, 94, 213-224. [CrossRef]

47. Lin, C.E.; Tsai, M.T.; Tsai, W.I.; Huang, C.L. Consumption power feedback unit for power electronics burn-in test. IEEE Trans. Ind. Electron. 1997, 44, 157-166. [CrossRef]

48. Li, M.; Gui, Y.; Vasquez, J.C.; Guerrero, J.M. Grid voltage modulated control of grid-connected voltage source inverters under unbalanced grid conditions. In Proceedings of the IECON 2017-43rd Annual Conference of the IEEE Industrial Electronics Society, Beijing, China, 29 October-1 November 2017; pp. 2510-2515.

49. Shi, X.; Zhu, J.; Li, L.; Lu, D.D.C. Model-predictive-based duty cycle control with simplified calculation and mutual influence elimination for AC/DC converter. IEEE J. Emerg. Sel. Top. Power Electron. 2018, 7, 504-514. [CrossRef]

50. Zhang, Y.; Qu, C.; Gao, J. Performance improvement of direct power control of pwm rectifier under unbalanced network. IEEE Trans. Power Electron. 2016, 32, 2319-2328. [CrossRef]

51. Zhu, Z.Q.; Hu, J. Investigation on switching patterns of direct power control strategies for grid-connected DC-AC converters based on power variation rates. IEEE Trans. Power Electron. 2011, 26, 3582-3598. [CrossRef]

(C) 2020 by the authors. Licensee MDPI, Basel, Switzerland. This article is an open access article distributed under the terms and conditions of the Creative Commons Attribution (CC BY) license (http://creativecommons.org/licenses/by/4.0/). 